\title{
Using Learning Objects to Teach Structural Engineering
}

\author{
http://dx.doi.org/10.3991/ijoe.v12i04.5014 \\ L.Andreatta-da-Costa \\ State University of Rio Grande do Sul and University Center UniRitter, Porto Alegre, Brazil
}

\begin{abstract}
This work explores learning objects - LO, which were developed to teach diagrams of bending moments and shear. From this Flash application, the students can explore mathematic and physical relations simulating different models of beams. The theoretical framework of this work are the constructivist learning principles, as active participation of the student, the importance of a prior knowledge and collaborative learning. This work also shows the using of this LO by engineering students in the course of Isostatic Structures.
\end{abstract}

Index Terms - structural engineering education, constructivism, active learning, collaborative learning

\section{INTRODUCTION}

Obtaining the bending moment and shear diagrams is an important issue of structural engineering, and is the basis of most structures disciplines of engineering courses. So always are welcome pedagogical strategies to help students better understand these concepts. The theoretical framework of this work are the constructivist principles ([1] e [2]).

\section{ACTIVITIES To DEMONSTRATE}

\section{A. Flash Animations}

This virtual environment, which is called GPA - Gerador Parametrizado de Avaliações [3], was developed on the research in the area of Engineering Education. Animations were done in Flash software, and have the objective to simulate different loads to different beams. Using these animations were then developed online experiments for students. Fig. 1 shows the case of an animation of a simply supported beam.

From these animations, the students can identify the changes occurring in the diagrams of shear and bending moment when the different model parameters are modified.

\section{B. Learning Activities}

Thus, the learning activities were developed in order to allow academics understand the Physical Concepts and Mathematical . In Fig. 2 , the First Activity It will appear.

In this first activity shown in Fig. 2, students are led to explore models and qualitatively describe what happens to the diagrams. In Fig. 3, which shows the activity 3 , from which the academic fill tables with the values in each of the magnitudes start points and obtaining the mathematical functions describing the diagrams.

In figure 4 we can observe the resolution of Activities 3 and 4 done by a student.

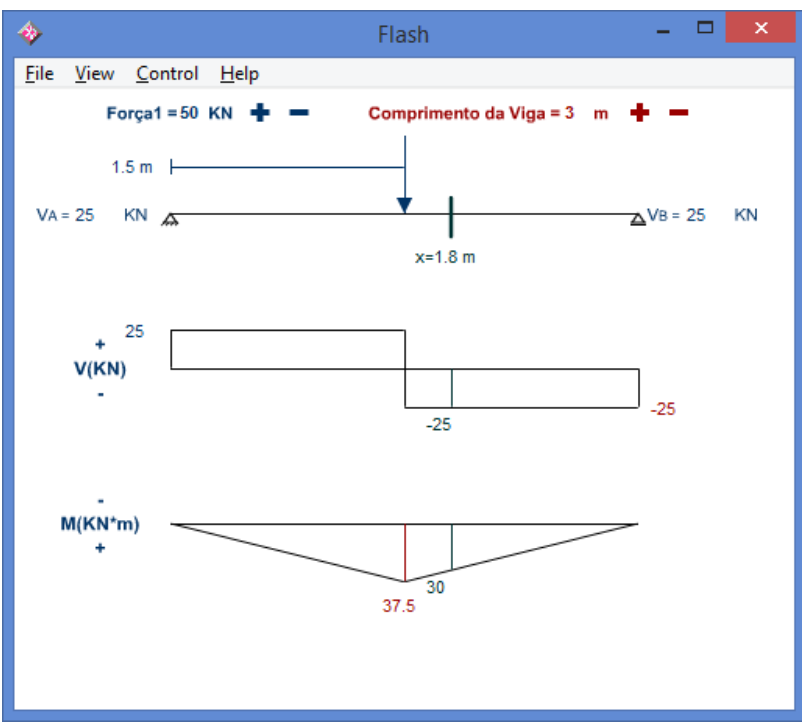

Figure 1. Animation of a simply supported beam

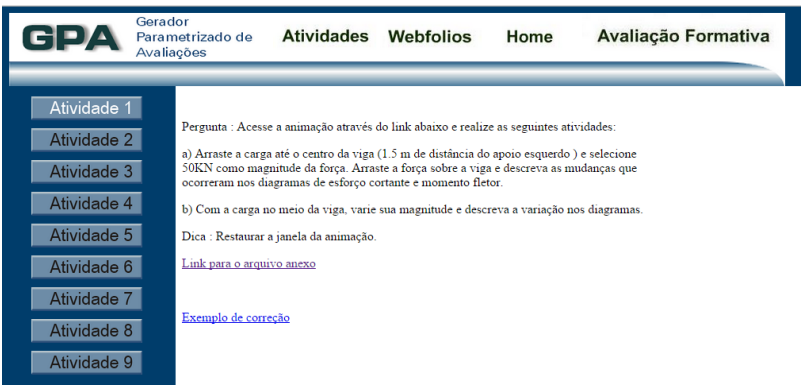

Figure 2. Learning Activity 1

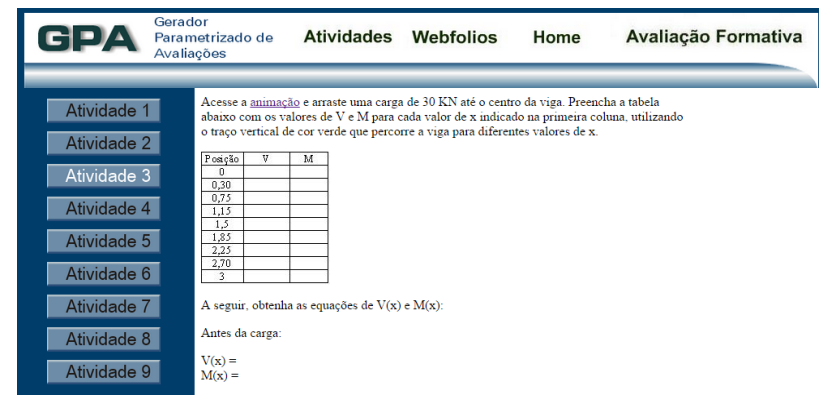

Figure 3. Third Activity

Models of distributed load are also used, as is shown on Fig. 5. In this model, it is possible to change the magnitude, the position and the extension of the load and the beam lenght. 
Atividade 3

Acesse a animação e arraste uma carga de $30 \mathrm{KN}$ até o centro da viga. Preencha a tabela abaixo com os valores de $\mathrm{V}$ e $\mathrm{M}$ para cada valor de $\mathrm{x}$ indicado na primeira coluna, utilizando o traço vertical de cor verde que percorre a viga para diferentes valores de $x$

$\$$

\begin{tabular}{|c|c|c|c|}
\hline Posição & V & $\mathrm{M}$ & A seguir, obtenha as equações de $V(x)$ e $M(x)$ : \\
\hline 0 & 15 & 0 & \\
\hline 0,30 & 15 & 4,5 & Antes da carga: \\
\hline 0,75 & 15 & 11,25 & \\
\hline 1,15 & 15 & 17,25 & $\begin{array}{l}V(x)=\{15 ; 0<x<1,5 \\
M(x)=\{15 x \cdot 0<x<15\end{array}$ \\
\hline 1,50 & -15 & 22,5 & \\
\hline 1,85 & -15 & 17,5 & Depois da carga: \\
\hline 2,25 & -15 & 11,25 & \\
\hline 2,70 & -15 & 4,5 & $V(x)=\{-15 ; 1,5<x<3$ \\
\hline 3,00 & -15 & 0 & $M(x)=\{-15 x+45 ; 1,5<x<3$ \\
\hline
\end{tabular}

Atividade 4

a) Preencha as tabelas abaixo de forma semelhante à atividade anterior, para valores da carga concentrada de $40 \mathrm{KN}$ e depois $50 \mathrm{KN}$. Após isso, escreva as equações de $\mathrm{V}(\mathrm{x})$ e $\mathrm{M}(\mathrm{x})$ para cada situação.

$\mathrm{P}=40 \mathrm{KN}$

\begin{tabular}{|c|c|c|c|}
\hline Posição & V & M & \multirow{4}{*}{$\begin{array}{l}\text { Antes da carga: } \\
V(x)=\{20 ; 0<x<1,5 \\
M(x)=\{20 x ; 0<x<1,5\end{array}$} \\
\hline 0 & 20 & 0 & \\
\hline 0,30 & 20 & 6 & \\
\hline 0,75 & 20 & 15 & \\
\hline 1,15 & 20 & 23 & \multirow{6}{*}{$\begin{array}{l}\text { Depois da carga: } \\
V(x)=\{-20 ; 1,5<x<3 \\
M(x)=\{-20 x+60 ; 1,5<x<3\end{array}$} \\
\hline 1,50 & -20 & 30 & \\
\hline 1,85 & -20 & 23 & \\
\hline 2,25 & -20 & 15 & \\
\hline 2,70 & -20 & 6 & \\
\hline 3,00 & -20 & 0 & \\
\hline
\end{tabular}

Figure 4. Resolution of activities 3 and 4

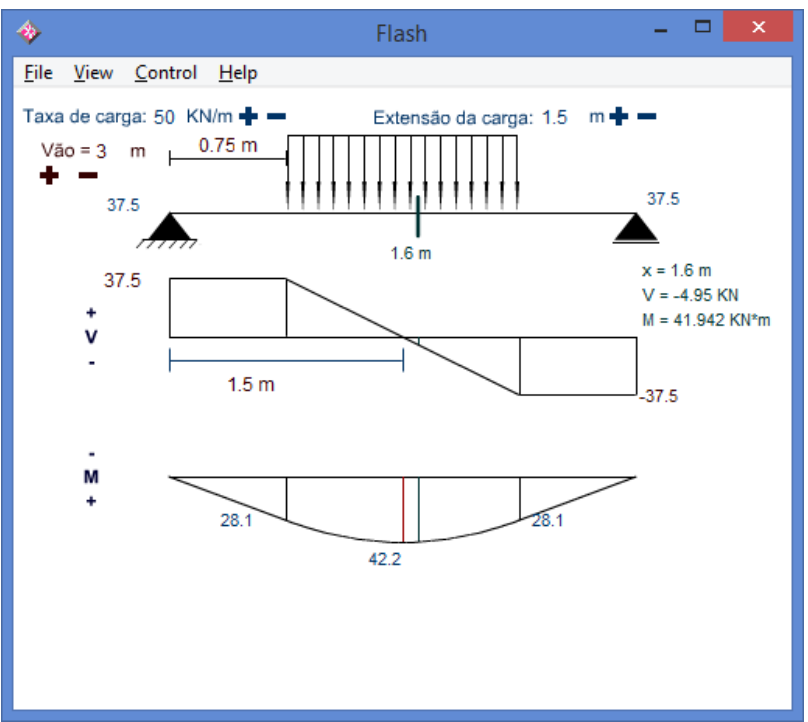

Figure 5. Distributed load activity

Fig. 6 shows activity 7, based on animation shown in Fig. 5, from which the academic can modify the values of the parameters, fill tables and obtain the mathematical functions.

\section{FORMATIVE EVALUATION}

The system also alow the communication between the teacher and the students. This strategies is important to improve educational process. These interactions are registred and can be used along the teaching-learning process ([4], [5] e [6]).

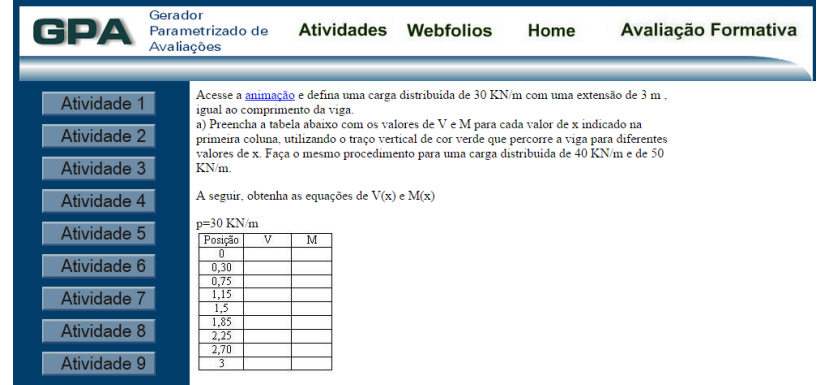

Figure 6. Seventh Activity

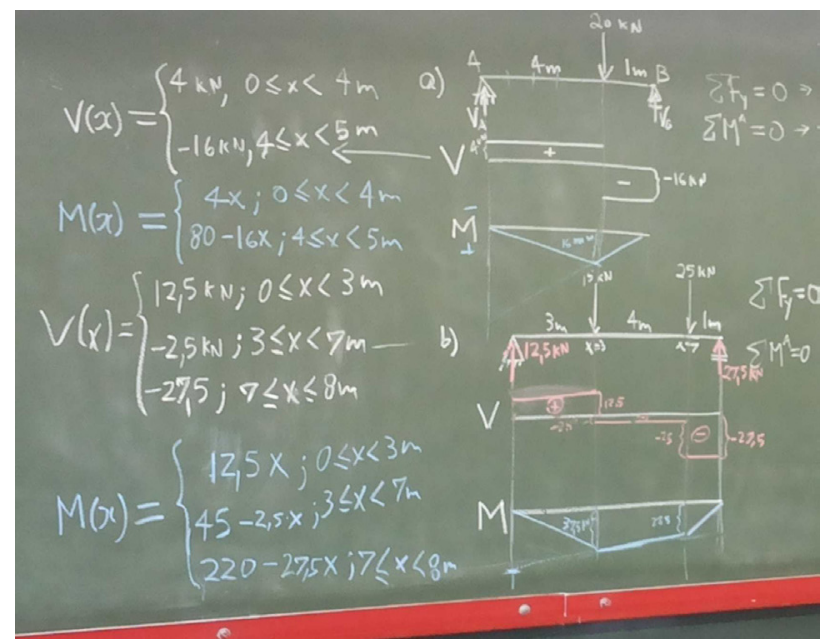

Figure 7. Traditional Method

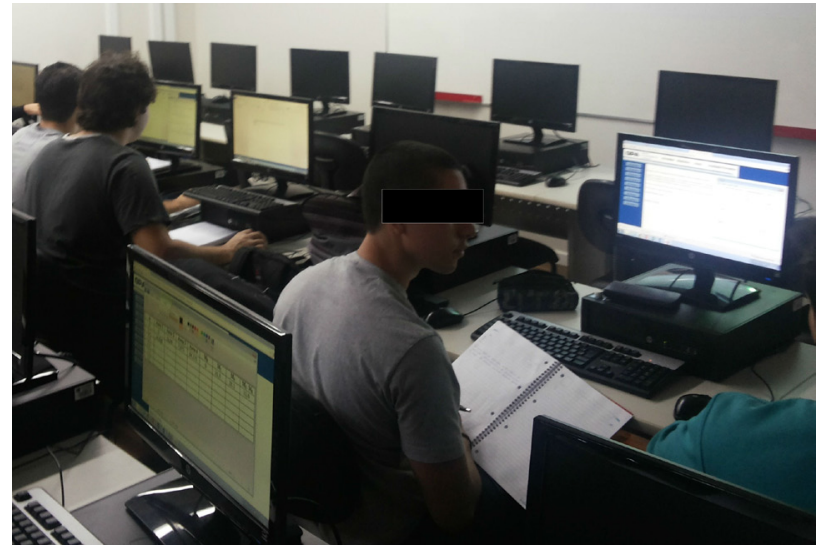

Figure 8. Alternative Method

\section{The EXPERIENCE IN The COURSE Of IsOSTATIC STRUCTURES}

In the first semester of 2015, GPA was used to teach Isostatic Structures, simultaneously to traditional method, as showed in Fig. 7 and Fig. 8.

The students performed nine activities which explored the virtual environment. It can be observed in the activities that the students were able to build the mathematical functions of the diagrams of bending moment and shear alternative way to the traditional method, which led to a good performance in the assessments. It is a discipline that traditionally students present difficulties.

The nine activities were applied in three different classes, and this work was evaluated (GPA Activity). Some interesting results were observed, especially when we compare the results of the grade 1 (before GPA Activity) 
TABLE I.

AVERAGES OBTAINED BY STUDENTS

\begin{tabular}{|l|c|c|c|}
\cline { 2 - 4 } \multicolumn{1}{c|}{} & Grade 1 & GPA Activity & Grade 2 \\
\hline First Class & 6 & 9,3 & 5,9 \\
\hline Second Class & 6,6 & 10 & 7,4 \\
\hline Third Class & 7,6 & 9,9 & 8 \\
\hline
\end{tabular}

with the results of the grade 2 (after GPA Activity). The grade 1 worked the previous matter to the diagrams, which was developed in traditional teaching way, while the grade 2 worked the contents of diagrams, which was worked on the GPA. In the Table 1 we can see the different averages obtained (Grade 1, GPA Activity and Grade 2).

It can be seen for example that the group (First Class) which obtained the lowest average in the GPA activity was the only one who did not get evolution in average of the Grade 1 (6.0) to the Grade 2 (5.9). Moreover, the best performance of the Grade 1 to the Grade 2 (from 6.6 to 7.4) occurred in the second group (Second Class), which had the best average in the GPA Activity.

Some qualitative analysis can be made, especially by some answers presented in activity 1 (Fig. 9 show an example), when students are asked to describe the changes in the diagrams when the load is moved along the simply supported beam. It can be observed that the responses have led students to understand in more detail the behavior of the diagrams. In traditional classes of this content are not usually proposed activities that require qualitative descriptions, which may limit the understanding of concepts worked.

\section{CONCLUSION}

This type of online experimentation helped to improve the teaching work, especially on the discipline of the Strength of Materials. The use of these Flash animations are easy to use, and can be easily performed on PCs with basic settings. The students which participated of the investigation said that the realization of these activities facilited the learning of the bending and shear diagrams.

From the performance of students, presented in the previous section, it can be concluded that the use of learning objects has great potential to enhance learning. Furthermore, carrying out activities that lead students to perform qualitative analyzes also represent an important way to improve learning.

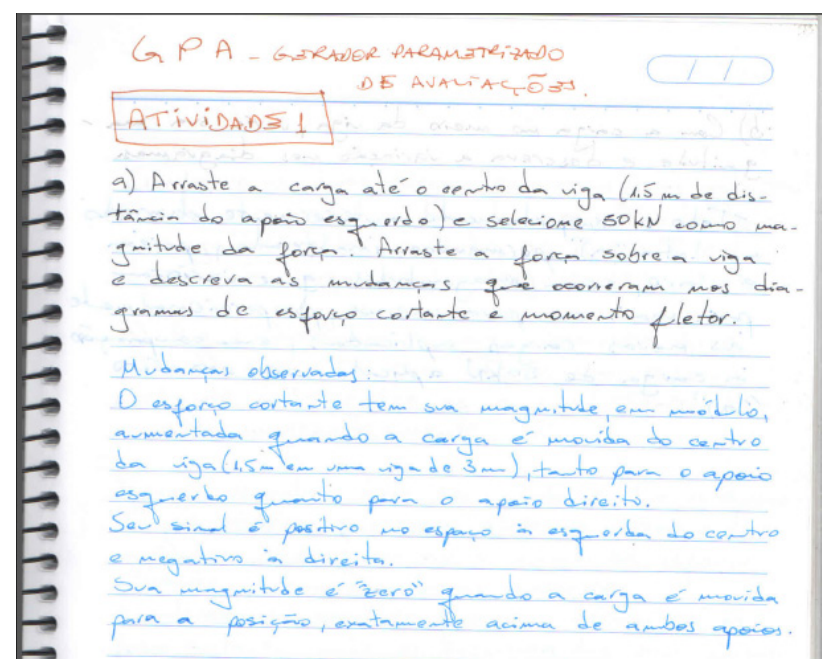

Figure 9. Answer of Activity 1

\section{ACKNOWLEDGMENT}

This research used the Fundação Liberato server for website hosting where investigations are made.

\section{REFERENCES}

[1] J. Piaget. "The Principles of Genetic Epistemology". New York: Basic Books, 1972.

[2] J. Piaget. "Biology and Knowledge". Chicago: University of Chicago, 1971.

[3] Gerador Parametrizado de Avaliações, Available from: http://gaia.liberato.com.br/cdbanca/home_main.htm, (03.07.2015)

[4] P. Saettler. "The evolution of american education technology". Libraries Unlimites: Englewood, Colorado. 1990.

[5] G. Salmon. "E-Moderating - The key to Teaching and Learning Online." Londres: Kogan Page, 2000..

[6] C. J. Marsh. A critical analysis of the use of formative assessment in schools. Educational Research and Policy Practice, 6, 25-29. 2007. http://dx.doi.org/10.1007/s10671-007-9024-z

\section{AUTHOR}

L.Andreatta-da-Costa ia with State University of Rio Grande do Sul and University Center UniRitter, Porto Alegre, Brazil (andreatta.luciano@gmail.com).

Submitted 05 September 2015. Published as resubmitted by the author 13 November 2015. 